\title{
Effectiveness of calcium - vitamin D supplementation on children with abnormal vitamin D status, low BMD, or both in Vietnam
}

Phuong Minh Nguyen ${ }^{1}$,

Linh Van Pham ${ }^{1}$,

Kien Trung Nguyen ${ }^{1}$,

Dat Tan Nguyen ${ }^{3}$,

Hanh Duong Nguyen ${ }^{1}$,

Nong Van Lai ${ }^{1}$,

Bach Hoang Nguyen ${ }^{4}$,

Yen Ngoc Diep ${ }^{3}$,

Thang Nguyen $4^{*}$

${ }^{1}$ Faculty of Medicine, Can Tho University of Medicine and Pharmacy, Can Tho, Vietnam

2 Faculty of Public Health, Can Tho University of Medicine and Pharmacy, Can Tho, Vietnam

3 Department of Biophysics, Sungkyunkwan University, Suwon, Republic of Korea

4 Faculty of Pharmacy, Can Tho University of Medicine and Pharmacy, Can Tho, Vietnam

\section{*Corresponding author:}

Thang Nguyen

nthang@ctump.edu.vn

\section{Keywords:}

Vitamin D and calcium supplementation; BMD; PTH; bone turnover markers; height and weight; Vietnam https://www.pharmacy.mahidol.ac.th/journal/ (c) Faculty of Pharmacy, Mahidol University (Thailand) 2021

\begin{abstract}
The effects of calcium and vitamin D supplementation on representative factors of bone health have been separately evaluated in different study populations worldwide, however, no data from solely one study population that comprehensively assess the supplementation outcomes on the skeletal system are available. We aimed to evaluate how calcium and vitamin D affect vitamin D level, bone mineral density (BMD), parathyroid hormone (PTH), and bone turnover markers as well as growth parameters in schoolchildren with abnormal vitamin D status and/or low BMD. An uncontrolled trial was carried out on 151 schoolchildren, aged 6-14, recruited from Can Tho City, Vietnam. The subjects were prescribed the combinations of calcium and vitamin $\mathrm{D}$ based on their age for a course of 6 months. After the intervention, the concentration of 250HD was significantly improved $(P<0.001)$ and only $5.3 \%$ of the subjects were found to have an abnormal 25OHD level. Only $10.6 \%$, compared with $66.89 \%$ before supplementation, had low BMD after the intervention $(P<0.05)$. The supplementation also increased weight and height and decreased P1NP. However, no significant changes were observed in $\beta$-CTx among boys and in PTH among the two genders. There was a negative correlation between vitamin $\mathrm{D}$ level and growth parameter, $\beta$-CTx. Linear regression analyses show a significant association between height, $\beta$-CTx level, and 25OHD level. In conclusion, the findings from our research provide a comprehensive assessment of various factors affected by calcium-vitamin $\mathrm{D}$ supplementation.
\end{abstract}

\section{INTRODUCTION}

Primarily, vitamin D is widely known as an important stimulator of intestinal calcium absorption ${ }^{1}$. In children, calcium absorption is an essential physiological process that promotes skeletal mineralization ${ }^{2}$, ensuring the normal calcification of human bone. The assessment of pediatric bone health can be achieved by using bone densitometry methods. Though there are a variety of modalities to measure bone mineral density (BMD) ${ }^{3}$, dual-energy $\mathrm{X}$-ray absorptiometry (DXA) is preferred method due to the availability, cost-effectiveness, and low-level of exposure to radiation ${ }^{4}$. In the DXA interpretation, both $\mathrm{T}$-score and Z-score are used to classify patients with low bone density. However, the Zscore is more appropriate to be used in children since it has been designed to compare the BMD of one child to those in an agematched and gender-matched population ${ }^{5}$. 
Parathyroid hormone $(\mathrm{PTH})$ and bone turnover markers (BTMs) also involve in human bone metabolism. PTH is a hormone released from parathyroid glands that regulates the serum level of calcium. Vitamin D deficiency leads to a reduction in serum calcium concentration. The hypocalcemia conditions trigger the greater release of PTH and subsequently increase the bone resorption ${ }^{6}$. BTMs are proteins released by osteoblasts or osteoclasts during the constant remodeling of bone. Procollagen type I Nterminal pro-peptide (P1NP) and $\beta$-isomerized C-terminal telopeptides $(\beta-\mathrm{CTx})$ are typical BTMs that reflect the bone formation and bone resorption, respectively ${ }^{7}$. The changes of serum PTH and BTMs in response to rickets treatment in children are more sensitive compared to bone mineral density, and therefore can be used to assess bone health in addition to BMD test ${ }^{8}$.

It is estimated that approximately one billion people, especially in South Asia, have abnormal vitamin D levels, including vitamin D insufficiency and deficiency ${ }^{9,10}$. Inadequate levels of vitamin $\mathrm{D}$ have been proven to be associated with severe pediatric health problems, especially rickets ${ }^{11}$ and osteoporotic fracture related to low $\mathrm{BMD}^{12}$. One potential strategy to reduce the prevalence of hypovitaminosis D and low BMD is calcium and vitamin D supplementation ${ }^{13}$. However, the doses for the prevention of calcium-vitamin D deficiency in children vary among countries and organizations. The Indian Academy of Pediatrics recommended a daily supplementation of $600-800 \mathrm{mg}$ calcium and $600 \mathrm{IU}$ of vitamin D for children aged 1-18 ${ }^{14}$. In the US, the American Academy of Pediatrics proposed a recommendation of daily $400 \mathrm{IU}$ vitamin D intake for all children from birth ${ }^{14}$, while in Europe, the proposed supplementation was up to $600 \mathrm{IU}$ of vitamin D for those in the 2-18-year-old group ${ }^{15}$.

In Vietnam, the previously recommended dose of vitamin D was 200 IU per day. However, the dose increased to 600 IU in consideration of a high prevalence of hypovitaminosis $D$ in Vietnamese children. In terms of calcium, a daily supply of $650 \mathrm{mg}, 700 \mathrm{mg}$, and $1000 \mathrm{mg}$ was recommended for children aged 6-7, 8-9, and 1019 , respectively ${ }^{16}$. Though the effects of calciumvitamin D supply on growth parameters, vitamin D level, BMD, PTH, and BTMs are separately reported in adults from different parts of the world ${ }^{17-19}$, data from solely one pediatric study population that comprehensively evaluate the supplementation effects on all aforementioned factors have been very limited. Therefore, we performed this study to assess the comprehensive effects of calcium - vitamin D intervention on a series of representative indicators of the skeletal system in schoolchildren in Can Tho City, Vietnam.

\section{MATERIALS AND METHODS}

\subsection{Study population}

In the research, 794 children from 6 to 14 were recruited from 3 elementary and 2 secondary schools in Can Tho, Vietnam between November 2012 and April 2016. Schools and classes were selected using probability proportional to size (PPS) sampling and simple random sampling, respectively. Subjects were measured in height and weight with light clothing and without shoes and examined for BMD as well as serum concentration of 25-hydroxyvitamin D (25OHD), $\mathrm{PTH}, \mathrm{P} 1 \mathrm{NP}$, and $\beta$-CTx. Exclusion criteria rejected children with chronic diseases that might significantly affect BMD (e.g., Cushing's syndrome, multiple myeloma, hyperthyroidism, and primary hyperparathyroidism), presence of acute diseases, different intervention at the time of the study, and participated refusals from parents. Children who presented vitamin D insufficiency/deficiency and/or low BMD were invited to attend the uncontrolled interventional study, which included a vitamin $\mathrm{D}$-calcium treatment regimen.

\subsection{Treatment protocol}

The doses of vitamin $\mathrm{D}$ and calcium used in the study were based on the recommendations of the National Institute of Nutrition ${ }^{20}$. Participants were divided into 2 groups of ages: 6-9-year-old and 10-14-year-old. In the 6-9-year-old group, children received $600 \mathrm{mg}$ elemental calcium and $400 \mathrm{IU}$ vitamin $\mathrm{D}_{3}$ daily (taken 1 Davita Bone effervescent twice daily after meals). In the 10-14-year-old group, children were prescribed $1,350 \mathrm{mg}$ elemental calcium and $460 \mathrm{IU}$ vitamin $\mathrm{D}_{3}$ daily (taken 1 Davita Bone effervescent twice daily after meals and 1 Calvit $D$ tablet in the afternoon). Both groups received combinations of calcium and vitamin D for a course of 6 months. Parents were instructed to dissolve each Davita Bone effervescent in $200 \mathrm{~mL}$ drinking water.

Study medications were delivered to parents or affiliated health workers once a month. The measurements of height and weight, BMD 
along with serum concentrations of 250HD, P1NP, $\beta-C T x$, and PTH were frequently performed during the first week after the intervention completed.

\subsection{Laboratory analysis}

In the research, $500 \mu 1$ serum samples, extracted from $3 \mathrm{~mL}$ venous blood samples, were stored at $-20^{\circ} \mathrm{C}$ at Can Tho University Hospital, Can Tho City, and transferred to the Medic Medical Center, Ho Chi Minh City, every 2 days for analyzing. The $25 \mathrm{OHD}$ concentration was measured by the High-Performance Liquid Chromatography-Mass Spectrometry (HPLC/MS), and the P1NP, $\beta$-CTx, and PTH were detected by using the Roche Elecsys 2010 (Roche Diagnostics, Indiana, USA). Vitamin D levels were classified as normal $(\geq 50 \mathrm{nmol} / \mathrm{L}$ or $\geq 20$ $\mathrm{ng} / \mathrm{mL})$, insufficiency $(37.5-50 \mathrm{nmol} / \mathrm{L}$ or $15-20$ $\mathrm{ng} / \mathrm{mL})$, and deficiency $(\leq 37.5 \mathrm{nmol} / \mathrm{L}$ or $\leq 15$ $\mathrm{ng} / \mathrm{mL})^{21-23}$. The BMD indication was measured at the distal third forearm by using the DXA (GE Lunar Prodigy Advance, Massachusetts, USA). The BMD values were set as normal $(\mathrm{Z}$-score $>-1 \mathrm{SD})$ and low $(\mathrm{Z} \text {-score }<-1 \mathrm{SD})^{24}$.

\subsection{Statistical analysis}

Data were analyzed by using SPSS version 20.0 (SPSS Inc., Chicago, Illinois, USA) and WHO Anthro-Plus. Continuous variables were displayed as means \pm SD and categorical variables were expressed as percentage and frequency. Comparisons between baseline and post-intervention values were assessed using t-tests for means and chisquare $\left(\chi^{2}\right)$ tests for percentages. A $P$ value of $<0.05$ was considered statistically significant.

\section{RESULTS}

Within the pool of 794 children, 344 were identified, with abnormal levels of 25OHD and/or low BMD, as eligible for the study. Out of 344 participants, 209 were enrolled into the vitamin Dcalcium treatment regimen. Over the course of the 6-month intervention, 42 adhered poorly to the therapy and another 16 refused to take blood tests. Finally, 151 children were taken into analysis, after the completed intervention (Figure 1).

The baseline and post-intervention characteristics of participants are reported in Table 1 . The subjects consisted of $42.4 \%$ boys

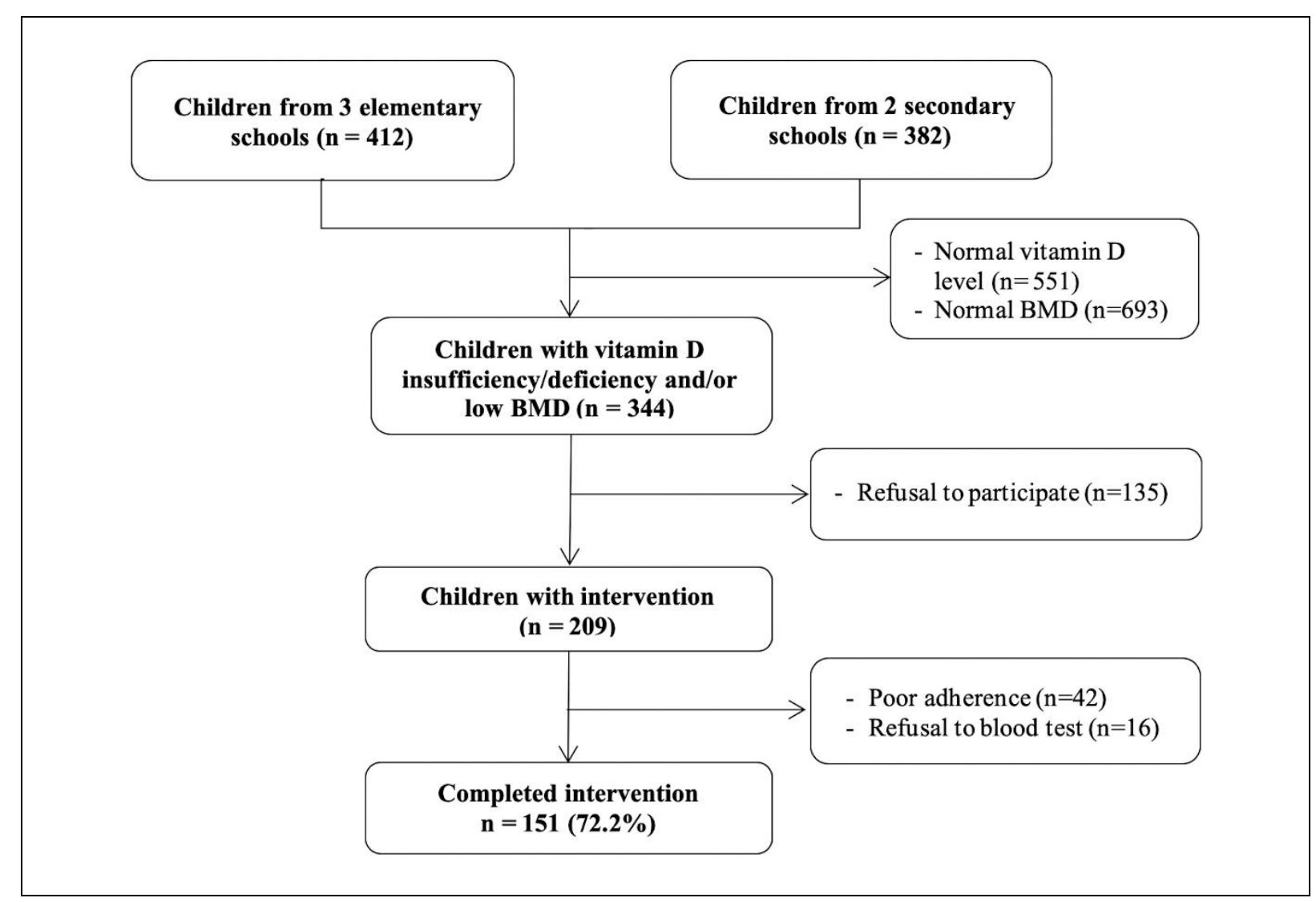

Figure 1. Flowchart of study population. (BMD : bone mineral density) 
Table 1. Characteristics of participants before and after calcium-vitamin D intervention.

\begin{tabular}{|c|c|c|c|}
\hline Characteristic & Baseline & Post-intervention & Test \\
\hline \multicolumn{4}{|l|}{ Gender, N (\%) } \\
\hline Boy & $64(42.4)$ & - & - \\
\hline Girl & $87(57.6)$ & - & - \\
\hline Age (years), mean \pm SD & $9.4 \pm 2.3$ & - & - \\
\hline Location, N (\%) & & - & - \\
\hline Urban & $6(3.97)$ & & \\
\hline Rural & $145(96.03)$ & & \\
\hline \multicolumn{4}{|l|}{ Nutritional status, N (\%) } \\
\hline Stunting & $50(33.1)$ & - & - \\
\hline Normal healthy & $87(57.6)$ & - & - \\
\hline Overweight/obesity & $14(9.3)$ & - & - \\
\hline \multicolumn{4}{|l|}{ Height $(\mathrm{cm})$, mean $\pm \mathrm{SD}$} \\
\hline Boy & $126.7 \pm 15.5$ & $133.1 \pm 16.2$ & $P<0.05$ \\
\hline Girl & $127.3 \pm 15.1$ & $132.7 \pm 16.0$ & $P<0.05$ \\
\hline \multicolumn{4}{|l|}{ Weight $(\mathrm{kg})$, mean $\pm \mathrm{SD}$} \\
\hline Boy & $27.87 \pm 12.94$ & $31.33 \pm 14.71$ & $P<0.001$ \\
\hline Girl & $25.63 \pm 8.63$ & $28.96 \pm 10.12$ & $P<0.001$ \\
\hline \multicolumn{4}{|l|}{ Vitamin D, N (\%) } \\
\hline Normal & $72(47.68)$ & $143(94.7)$ & $P<0.05$ \\
\hline Insufficiency & $48(31.79)$ & $8(5.3)$ & $P<0.05$ \\
\hline Deficiency & $31(20.53)$ & $0(0)$ & $P<0.05$ \\
\hline \multicolumn{4}{|l|}{$250 H D(n m o l / L)$, mean $\pm \mathrm{SD}$} \\
\hline Boy & $66.48 \pm 24.95$ & $89.28 \pm 24.76$ & $P<0.001$ \\
\hline Girl & $65.65 \pm 24.21$ & $90.07 \pm 23.62$ & $P<0.001$ \\
\hline \multicolumn{4}{|l|}{ BMD, N (\%) } \\
\hline Normal & $50(33.11)$ & $135(89.4)$ & $P<0.05$ \\
\hline Low & $101(66.89)$ & $16(10.6)$ & $P<0.05$ \\
\hline BMD $\left(\mathrm{g} / \mathrm{cm}^{2}\right)$, mean $\pm \mathrm{SD}$ & $0.284 \pm 0.044$ & $0.302 \pm 0.051$ & $P<0.001$ \\
\hline Normal 25OHD children & $0.277 \pm 0.041$ & $0.298 \pm 0.043$ & $P<0.001$ \\
\hline 25OHD insufficiency children & $0.297 \pm 0.039$ & $0.298 \pm 0.061$ & $P=0.869$ \\
\hline 25OHD deficiency children & $0.322 \pm 0.062$ & $0.35 \pm 0.071$ & $P=0.003$ \\
\hline \multicolumn{4}{|l|}{ PTH $(\mathrm{pg} / \mathrm{mL})$, mean \pm SD } \\
\hline Boy & $26.71 \pm 10.1$ & $25.61 \pm 12, .6$ & $P=0.5$ \\
\hline Girl & $30.71 \pm 11.6$ & $27.72 \pm 10.8$ & $P=0.08$ \\
\hline \multicolumn{4}{|l|}{$\mathbf{P} 1 \mathbf{N P}(\mathrm{ng} / \mathrm{mL})$, mean $\pm \mathrm{SD}$} \\
\hline Boy & $462.07 \pm 216.75$ & $352.19 \pm 196.16$ & $P=0.003$ \\
\hline Girl & $441.98 \pm 213$ & $368.58 \pm 131$ & $P=0.007$ \\
\hline \multicolumn{4}{|l|}{$\boldsymbol{\beta}-\mathbf{C T} \mathbf{x}(\mathrm{pg} / \mathrm{mL})$, mean $\pm \mathrm{SD}$} \\
\hline Boy & $837.67 \pm 341.42$ & $875.81 \pm 368.18$ & $P=0.5445$ \\
\hline Girl & $835.15 \pm 333.17$ & $943.47 \pm 262.1$ & $P=0.0182$ \\
\hline
\end{tabular}

25OHD, 25-hydroxyvitamin D; BMD, bone mineral density; P1NP, procollagen type I N-terminal propeptide; $P T H$, parathyroid hormone; $\beta$-CTx, $\beta$-isomerized $C$-terminal telopeptides.

and $57.6 \%$ girls with the mean age of 9.4. Majority of subjects $(96.03 \%)$ came from the rural area. The proportions of stunted, normal healthy, and overweight-obese children were $33.1 \%, 57.6 \%$, and $9.3 \%$, respectively.

At the beginning of the study, the abnormal concentration of 25OHD was found in $52.32 \%$ children, in which $20.5 \%$ were even below 37.5 $\mathrm{nmol} / \mathrm{L}$. However, after the intervention, the mean level of serum 25OHD was significantly improved by $22.8 \mathrm{nmol} / \mathrm{L}(P<0.001)$ among boys and by $24.42 \mathrm{nmol} / \mathrm{L}(P<0.001)$ among girls. No children with vitamin $\mathrm{D}$ deficiency remaining were found $(P<0.05)$. A significant improvement was also seen in BMD, only $10.6 \%$ of the participants had low BMD after calcium-vitamin D therapy, compared with $66.89 \%$ at enrolment $(P<0.05)$. The analysis showed a decrease in P1NP and an increase in weight and height in both genders. However, the changes in $\beta$-CTx were observed only in girls, with an increase of $108.32 \mathrm{pg} / \mathrm{mL}$. The concentration of PTH was not statistically different compared with after calcium-vitamin D supplementation.

The relationship between vitamin Dcalcium supplementation and the level of circulating 25OHD, BMD with adjusted for age, gender, and PTH level was examined by multivariate logistic regression analyses. Gender was significantly associated with BMD $(P<0.01)$, but no association was found between gender and vitamin $\mathrm{D}$ level $(P=0.417)$. The association between age and $\operatorname{BMD}(P<0.01)$, 
Table 2. Correlation between vitamin D-calcium supplementation and growth parameter, circulating concentration of 25OHD, BMD, PTH as well as BTMs.

\begin{tabular}{lcc}
\hline Characteristic & $\boldsymbol{r}$ & $\boldsymbol{P}$-value \\
\hline Height $(\mathrm{cm})$ & -0.4558 & $<0.01$ \\
Weight $(\mathrm{kg})$ & -0.3703 & $<0.01$ \\
BMD $\left(\mathrm{g} / \mathrm{cm}^{2}\right)$, & -0.1340 & 0.1009 \\
PTH $(\mathrm{pg} / \mathrm{mL})$ & -0.1374 & 0.0926 \\
P1NP $(\mathrm{ng} / \mathrm{mL})$ & -0.1323 & 0.1054 \\
$\boldsymbol{\beta}$-CTx $(\mathrm{pg} / \mathrm{mL})$ & -0.3259 & $<0.01$ \\
\hline
\end{tabular}

25OHD, 25-hydroxyvitamin D; BMD, bone mineral density; BTMs, bone turnover markers; PINP, procollagen type I Nterminal propeptide; PTH, parathyroid hormone; $\beta$-CTx, $\beta$-isomerized $C$-terminal telopeptides.

vitamin D level $(P<0.01)$ were observed, while PTH was not associated with either BMD $(P=0.097)$ or vitamin $\mathrm{D}(P=0.572)$ concentration.

The relationship between vitamin Dcalcium intervention and growth parameters, circulating concentration of $25 \mathrm{OHD}, \mathrm{PTH}$, BTMs, and BMD was evaluated by correlation and linear regression analyses. There were no correlations between 25OHD levels and BMD, $\mathrm{PTH}$, and P1NP. But a negative correlation between vitamin $\mathrm{D}$ concentration and height, weight, $\beta$-CTx was observed (Table 2). In the linear regression analyses, height and $\beta$-CTx level were significantly associated with $25 \mathrm{OHD}$ level. However, weight, BMD, P1NP, PTH were not associated with 25OHD level (Table 3).

Table 3. Linear regression analysis between vitamin D-calcium supplementation and growth parameter, circulating concentration of 25OHD, BMD, PTH as well as BTMs.

\begin{tabular}{lcc}
\hline Characteristic & $\boldsymbol{\beta}$ coefficients & $\boldsymbol{P}$-value \\
\hline Height $(\mathrm{cm})$ & -0.397484 & 0.003 \\
Weight $(\mathrm{kg})$ & 0.017409 & 0.904 \\
BMD $\left(\mathrm{g} / \mathrm{cm}^{2}\right)$, & -0.061506 & 0.492 \\
PTH $(\mathrm{pg} / \mathrm{mL})$ & 0.015654 & 0.836 \\
P1NP $(\mathrm{ng} / \mathrm{mL})$ & 0.090132 & 0.331 \\
$\boldsymbol{\beta}$-CTx $(\mathrm{pg} / \mathrm{mL})$ & -0.317081 & 0.001 \\
\hline
\end{tabular}

25OHD, 25-hydroxyvitamin D; BMD, bone mineral density; BTMs, bone turnover markers; P1NP, procollagen type I $N$-terminal propeptide; PTH, parathyroid hormone; $\beta$-CTX, $\beta$-isomerized $C$-terminal telopeptides.

\section{DISCUSSION}

We evaluated the relationship between vitamin $\mathrm{D}$ and calcium supplementation and growth parameters as well as serum concentration of 25OHD, BMD, PTH, and BTMs. The mean 25OHD level significantly increased in both genders, with $94.7 \%$ of the subjects having a normal level after the intervention. The next significant change was seen in the improvement of BMD, with $89.4 \%$ of children within normal range after the intervention. The supplementation also affected the other factors, with a statistically significant increase in height and weight and a decrease in P1NP. However, no significant effects on $\beta$-CTx among boys and PTH levels among the two genders were observed.

The 25OHD level of the participants before the intervention, although carrying out on a sample of children with abnormal vitamin D status, is significantly higher compared to those in other geographic regions. Kurth et at. reported a mean $25 \mathrm{OHD}$ concentration of $47.8 \mathrm{nmol} / \mathrm{L}$ among children in the 1-17 age group in Germany $^{25}$, much lower than the mean of 66.48 $\mathrm{nmol} / \mathrm{L}$ among boys and $65.65 \mathrm{nmol} / \mathrm{L}$ among girls in our study. The other study conducted in Korean children aged 10-18 indicated an average $25 \mathrm{OHD}$ of $44.2 \mathrm{nmol} / \mathrm{L}$, with $28.1 \%$ and $78.1 \%$ of children having a 25OHD level less than $75 \mathrm{nmol} / \mathrm{L}$ and $50 \mathrm{nmol} / \mathrm{L}$, respectively ${ }^{26}$. In addition, vitamin $D$ status in regions with abundant sunshine such as Middle East was also lower in comparison to our study. Saliba et al. found a mean serum $25 \mathrm{OHD}$ of $50.3 \mathrm{nmol} / \mathrm{L}$ among boys and $59.9 \mathrm{nmol} / \mathrm{L}$ among girls under 19 years old in Israel ${ }^{27}$. Even in Vietnam, Laillou et al. also reported a lower level of $25 \mathrm{OHD}$ (43.4 $\mathrm{nmol} / \mathrm{L}$ ) in children aged $0-5^{28}$.

The differences between our study and these studies may be explained by several reasons. First of all, the measurement of 25OHD concentration in our study was performed by using HPLC/MS that provides a more reliable value than chemiluminescent immunoassay (CLIA) and radioimmunoassay (RIA) used in the above 
studies ${ }^{29}$. Secondly, the differences may come from different latitudes, skin pigmentation, and clothing style. Individuals from high latitudes or with dark skin require a much greater sun exposure time, sometimes impractical, to synthesize the standard amount of vitamin $\mathrm{D}^{30}$. Also, people with traditional clothing styles, usually in Asian countries, were revealed to have lower vitamin D status in comparison to those in Western style ${ }^{31}$. Lastly, the differences of vitamin D levels in individuals living within the same country may be due to lifestyle. Younger children seem to have more indoor life due to safety reasons and therefore have lower exposure to sunlight.

Two studies including data from infants and toddlers confirmed the improvement of serum 250HD concentration after the intervention, although the improvement levels were significantly higher compared to our study. In the US, 40 children with hypovitaminosis D were randomly assigned to one of three treatment regimens for 6 weeks ${ }^{32}$. The treatment was found to triple the 25OHD concentration in all regimens. In Finland, a similar intervention indicated a mean increase by $35 \mathrm{nmol} / \mathrm{L}, 71$ $\mathrm{nmol} / \mathrm{L}$, and $100 \mathrm{nmol} / \mathrm{L}$ among infants receiving daily 10,30 , and $40 \mu \mathrm{g}$ vitamin $\mathrm{D}$, respectively, for 3 months ${ }^{33}$. Differences in the dose of vitamin $\mathrm{D}$ and treatment period are likely to explain the outcome differences among these studies.

The next significant change was seen in the improvement of BMD, affecting children with both normal and deficiency vitamin D status. This effect was inconsistent with findings of the earlier review, which observed the BMD improvement after calcium-vitamin D supply, statistically, only in children with abnormal vitamin D level ${ }^{12}$. Possible explanations for differences in the vitamin D affects between our study and the previous review may lie in the measurement methods of BMD (DXA vs. DXA/pQCT), the measured sites (forearm vs. hip, lumbar spine and forearm), and the average vitamin $\mathrm{D}$ level at baseline $(66.5 \mathrm{nmol} / \mathrm{L}$ vs. $17.7-49.5 \mathrm{nmol} / \mathrm{L})$.

The relationship between calcium-vitamin D supplementation and growth parameters has been reported in previous studies. In India, a randomized, controlled study performed on 2-5year-old children with vitamin $\mathrm{D}$ deficiency showed an increase in both height and weight ${ }^{34}$. In another randomized controlled study among US children aged 12-15 years, an average increase of $0.9 \mathrm{~cm}$ in height was reported, but no significant effects of calcium-vitamin D on weight were observed $^{35}$. Possibly, the total dose of calcium- vitamin D and the follow-up duration in the Indian study were appropriate to observe an effect on weight, since the participants in this study, at baseline, had previously been injected a single dose of $300,000 \mathrm{IU}$ vitamin D along with oral calcium for 3 months before the official calciumvitamin intervention for a duration of 9 months.

In terms of PTH and BTMs, in children, very few studies on the effects of vitamin $D$ and calcium have been done so far. A systematic review carried out on clinical trials of vitamin $D$ supplementation among adults indicated a decrease in PTH concentration ${ }^{36}$. In a study in Norway, 399 adults were randomized to either 20,000 IU of vitamin D per week or placebo for 4 months ${ }^{37}$. Although the supplementation did decrease the P1NP concentration, it did not statistically change the $\beta$-CTx level as found among girls in our study. Further pediatric investigation on the effect of vitamin $\mathrm{D}$ and calcium supply on PTH and $\beta$-CTx should be made to confirm our findings.

Our study has some limitations that should be taken into consideration. Firstly, the study participants are not a nationally representative sample since they are solely originated from Can Tho City, Vietnam. On another hand, it is impossible to omit the coeffects of vitamin D and calcium contained in dietary (e.g., egg yolks, shrimp, cow's milk) as the ingredients in daily meals vary among different families. However, such a low amount in dietary is not likely to significantly change the post-intervention values. Finally, the dropout rate in our study is relatively high $(27.8 \%)$, mainly due to poor adherence to the treatment regimen. This might be because the majority of households come from rural areas in which many parents were with educational limitations. Fortunately, the remaining number of participants after the intervention $(\mathrm{n}=151)$ did not make the data unpowered since the obtained results are still consistent with previous studies. However, our study has several considerable strengths. To our knowledge, it is the first report that evaluates the effectiveness of calcium and vitamin D intervention on various factors, including growth parameters, 25OHD level, BMD, PTH, and BTMs, while previous studies separately assess the supplementation outcomes on these factors. This research offers a comprehensive overview of the effects of calcium and vitamin $\mathrm{D}$, especially in Vietnam, where very few pediatric data have been published. Moreover, a significant improvement is made upon completing the study 
as nearly all participated subjects achieve normal BMD and 25OHD levels. Additionally, we measure the level of 25OHD by using HPLC/MS which is considered the gold standard for vitamin $\mathrm{D}$ testing. The advantages of this method lie in its accuracy and improved specificity/sensitivity in comparison with CLIA and RIA ${ }^{38}$.

In consideration of such an impressive improvement in indicating factors of bone health after the intervention, awareness should be generated about the importance of calciumvitamin D and supplementation strategy need to be established nationally. A significant increase in $\beta$-CTx among girls when compared to that of boys suggests demand for evaluating the contribution of genders in improving $\beta$-CTx level. In addition, further research assessing the effects of calcium-vitamin D intervention on PTH in children in Vietnam or in the same regional countries need to be conducted to validate the results of this study.

\section{CONCLUSIONS}

In conclusion, this study evaluated the effects of vitamin D and calcium on growth parameters as well as 25OHD level, BMD, PTH, and BTMs. The momentous changes were seen in the improvement of 25OHD level and BMD, with nearly all children within normal range after the intervention. The supplementation also affected the other factors, with an improvement in height and weight and a decrease in P1NP. Further investigation needs to be carried out to test the effects of the intervention on $\beta$-CTx and PTH levels. Our findings offer a comprehensive assessment of numerous factors affected by calcium and vitamin D supplementation.

\section{ACKNOWLEDGMENTS}

We would like to express our gratitude to nurses and technicians from Can Tho University Hospital for their support in collecting data.

\section{Conflict of interest}

The authors declare no conflict of interest.

\section{Funding}

None to declared.

\section{Ethics approval}

The study protocol was approved by the institutional review board of the Can Tho University of Medicine and Pharmacy. Written consents were fully obtained from parents of participants prior to the beginning of the study.

\section{Article info:}

Received March 18, 2020

Received in revised form May 13, 2020

Accepted July 26, 2020

\section{REFERENCES}

1. Christakos S, Dhawan P, Porta A, Mady LJ, Seth T. Vitamin D and intestinal calcium absorption. Mol Cell Endocrinol. 2011;347(1-2):25-9.

2. Bonjour JP. Calcium and phosphate: A duet of ions playing for bone health. J Am Coll Nutr. 2011;30 (August):438S-448S.

3. Specker BL, Schoenau E. Quantitative bone analysis in children: Current methods and recommendations. J Pediatr. 2005;146(6):726-31.

4. Crabtree NJ, Arabi A, Bachrach LK, Fewtrell M, El-Hajj Fuleihan G, Kecskemethy HH, et al. Dual-energy x-ray absorptiometry interpretation and reporting in children and adolescents: The revised 2013 ISCD pediatric official positions. J Clin Densitom. 2014;17(2):225-42.

5. Chiarpenello J. Diagnosis of Osteoporosis in Children. Endocrinol Metab Syndr. 2016;5(3):2-7.

6. Murrills R. Parathyroid Hormone and Bone Cells. Clin Rev Bone Miner Metab. 2006;4(4):233-57.

7. Vasikaran S, Eastell R, Bruyère O, Foldes AJ, Garnero $\mathrm{P}$, Griesmacher A, et al. Markers of bone turnover for the prediction of fracture risk and monitoring of osteoporosis treatment: A need for international reference standards. Osteoporos Int. 2011;22(2):391-420.

8. Schwetz V, Trummer C, Pandis M, Grübler MR, Verheyen N, Gaksch M, et al. Effects of vitamin D supplementation on bone turnover markers: A randomized controlled trial. Nutrients. 2017;9(5):1-11.

9. Sahota O. Understanding vitamin D deficiency. Age Ageing. 2014;43(5):589-91.

10. Palacios C, Lilliana G. Is vitamin D deficiency a major global public health problem? J Steroid Biochem Mol Biol. 2014;138-45.

11. Sahay M, Sahay R. Rickets-vitamin D deficiency and dependency. Indian J Endocrinol Metab. 2012;16(2):164.

12. Winzenberg T, Powell S, Shaw KA, Jones G. Effects of vitamin $\mathrm{D}$ supplementation on bone density in healthy children: Systematic review and meta-analysis. BMJ. 2011;342(7791):267.

13. Weaver CM, Alexander DD, Boushey CJ, DawsonHughes B, Lappe JM, LeBoff MS, et al. Calcium plus vitamin D supplementation and risk of fractures: an updated meta-analysis from the National Osteoporosis Foundation. Osteoporos Int. 2016;27(1):367-76.

14. Khadilkar A, Khadilkar V, Chinnappa J, Rathi N, Khadgawat R, Balasubramanian S, et al. Prevention and treatment of vitamin $\mathrm{D}$ and calcium deficiency in children and adolescents: Indian Academy of Pediatrics (IAP) guidelines. Indian Pediatr. 2017;54(7):567-73.

15. Braegger C, Campoy C, Colomb V, Decsi T, Domellof M, Fewtrell M, et al. Vitamin d in the healthy European paediatric population. J Pediatr Gastroenterol Nutr. 2013;56(6):692-701.

16. Vu TTH, Tran TN. Recommendation for calcium-vitamin D supplementation in Vietnamese children [Internet]. National Institute of Nutrition. 2016. Available from: http://viendinhduong.vn/vi/tin-tuc/diem-moi-ve-nhucau-khuyen-nghi-vitamin-d-va-canxi.html/. 
17. Lerchbaum E, Trummer C, Theiler-Schwetz V, Kollmann M, Wölfler M, Pilz S, et al. Effects of vitamin $\mathrm{D}$ supplementation on bone turnover and bone mineral density in healthy men: A post-hoc analysis of a randomized controlled trial. Nutrients. 2019;11(4):731.

18. Rad EY, Saboori S, Falahi E, Djalali M. Vitamin D supplementation decreased body weight and body mass index of Iranian type-2 diabetic patients: A randomised clinical trial study. Malays J Nutr. 2018;24(1):1-9.

19. Lotito A, Teramoto M, Cheung M, Becker K, Sukumar D. Serum parathyroid hormone responses to vitamin D supplementation in overweight/obese adults: A systematic review and meta-analysis of randomized clinical trials. Nutrients. 2017;9(3):241.

20. Ministry of Health. National Strategy on Nutrition for the period 2011-2020 and Future Strategy for 2030. Medical Publshing House. Ha Noi; 2012:1-39.

21. Cole CR, Grant FK, Tangpncha V, Dawn Swaby-Ellis E, Smith JL, Jacques A, et al. 25-Hydroxyvitamin D status of healthy, low-income, minority children in Atlanta, Georgia. Pediatrics. 2010;125(4):633-9.

22. Scientific Advisory Committee on Nutrition. Update on Vitamin D: Position statement by the Scientific Advisory Committee on Nutrition. London: TSO (The Stationery Office); 2007:1-73.

23. Saintonge S, Bang H, Gerber L. Implications of a new definition of vitamin D deficiency in a multiracial in adolescent population: the National Health and Nutrition Examination Survey III. Pediatrics. 2009;123(3):797-803.

24. Jones G, Ma D, Cameron F. Bone Density Interpretation and Relevance in Caucasian Children Aged 9-17 Years of Age: Insights From a Population-Based Fracture Study. J Clin Densitom. 2006;9(2):202-9.

25. Kurth BM, Kamtsiuris P, Hölling H, Schlaud M, Dölle $\mathrm{R}$, Ellert U, et al. The challenge of comprehensively mapping children's health in a nation-wide health survey: Design of the German KiGGS-Study. BMC Public Health. 2008;8:1-8.

26. Kim SH, Oh MK, Namgung R, Park MJ. Prevalence of 25-hydroxyvitamin D deficiency in Korean adolescents: association with age, season and parental vitamin D status. Public Health Nutr. 2014;17(1):122-30.

27. Saliba W, Rennert HS, Kershenbaum A, Rennert G. Serum 25(OH)D concentrations in sunny Israel. Osteoporos Int. 2012;23(2):687-94.

28. Laillou A, Wieringa F, Tran TN, Van PT, Le BM, Fortin $\mathrm{S}$, et al. Hypovitaminosis $\mathrm{D}$ and mild hypocalcaemia are highly prevalent among young Vietnamese children and women and related to low dietary intake. PLoS One. 2013;8(5):e63979.

29. Snellman G, Melhus H, Gedeborg R, Byberg L, Berglund L, Wernroth L, et al. Determining vitamin D status: A comparison between commercially available assays. PLoS One. 2010;5(7):3-9.

30. Webb A, Engelsen O. Calculated Ultraviolet Exposure Levels for a Healthy Vitamin D Status. Photochem Photobiol. 2006;82(6):1697-703.

31. Petersen RA, Damsgaard CT, Dalskov SM, Sorensen LB, Hjorth MF, Ritz C, et al. Vitamin D status and its determinants during autumn in children at northern latitudes: A cross-sectional analysis from the optimal well-being, development and health for Danish children through a healthy New Nordic Diet (OPUS) School Meal Study. Br J Nutr. 2016;115(2):239-50.

32. Gordon CM, Williams ALB, Feldman HA, May J, Sinclair L, Vasquez A, et al. Treatment of hypovitaminosis $\mathrm{D}$ in infants and toddlers. J Clin Endocrinol Metab. 2008;93(7):2716-21.

33. Holmlund-Suila E, Viljakainen H, Hytinantti T, Lamberg-Allardt C, Andersson S, Mäkitie O. High-dose vitamin D intervention in infants - Effects on vitamin D status, calcium homeostasis, and bone strength. J Clin Endocrinol Metab. 2012;97(11):4139-47.

34. Rao Y, Midha T, Tripathi P, Singh S, Sharma RD, Arora $S$. Effect of vitamin d supplementation on growth parameters in children with vitamin D deficiency. J Pediatr Sci. 2016;8:e263.

35. Ganmaa D, Stuart JJ, Sumberzul N, Ninjin B, Giovannucci E, Kleinman K, et al. Vitamin D supplementation and growth in urban Mongol school children: Results from two randomized clinical trials. PLoS One. 2017;12(5):1-13.

36. Björkman M, Sorva A, Tilvis R. Responses of parathyroid hormone to vitamin D supplementation: A systematic review of clinical trials. Arch Gerontol Geriatr. 2009;48(2):160-6.

37. Jorde R, Stunes AK, Kubiak J, Joakimsen R, Grimnes G, Thorsby PM, et al. Effects of vitamin D supplementation on bone turnover markers and other bone-related substances in subjects with vitamin $\mathrm{D}$ deficiency. Bone. 2019;124:7-13.

38. Galior K, Ketha H, Grebe S, Singh RJ. 10 years of 25hydroxyvitamin-D testing by LC-MS/MS-trends in vitamin-D deficiency and sufficiency. Bone Reports. 2018;8:268-73. 